\title{
Research on the Influencing Factors and Entrepreneurship Supporting Strategies of Chinese Migrant Workers Returning Home
}

\author{
Jianchun Yang ${ }^{1}$ Bo Zhu ${ }^{2, *}$ Yu Han ${ }^{3}$ \\ ${ }^{1}$ Guizhou University of Finance and Economics, Guizhou, China \\ ${ }^{2}$ Guizhou University of Finance and Economics, Guizhou, China \\ ${ }^{3}$ Guizhou University of Finance and Economics, Guizhou, China \\ *Corresponding author. Email: 891826466@qq.com
}

\begin{abstract}
The team of migrant workers going home and start a new job in my country is gradually growing, and their aspiration to start an undertaking has also gradually strengthened, but their entrepreneurial behaviour is affected by many factors. The employment and entrepreneurship of migrant workers is related to the implementation of the "rural revitalization" strategy, and plays a major role in reducing poverty and promoting economic growth. This paper is based on the research of relevant literature and the investigation of the factors influencing migrant workers starting a new career with enthusiasm. The research on the influencing factors of returning home to start a business mainly focuses on the four aspects of starting a business, entrepreneurial environment, entrepreneurial behaviour and entrepreneurial performance. By analysing the influencing the factors, we propose strategies to support going home and work hard to start a new business.
\end{abstract}

Keywords: Migrant workers, returning home to start a business, Factors influencing entrepreneurship, Entrepreneurial support strategies.

\section{INTRODUCTION}

In the context of the global economic weakness, my country's migrant workers are facing the dilemma of urban industrial transformation and the shortage of middle and low-end jobs in different places, which has caused many migrant workers to be forced to return to their hometowns [1]. The new crown epidemic that occurred in 2020 will have an adverse impact on migrant workers who are migrant workers, which will further expose migrant workers to a severe employment situation. In recent years, my country has issued a series of support policies for returning home with enthusiasm and left their job to start a new career, which has greatly promoted the enthusiasm of migrant workers [2]. According to the "2019 Migrant Workers Monitoring Survey Report", the total number of migrant workers in 2019 reached 290.77 million, an increase of 2.41 million over the previous year, an increase of $0.8 \%$, and the scale of migrant workers continued to expand. Among migrant workers, 99.17 million migrant workers were employed in the province, an increase of 2.45 million from the last year, an increase of $2.5 \%$, and 75.08 million migrant workers across the province, a decrease of 860,000 from the last year, a decrease of $1.1 \%$ [3]. With the strong support of government policies, Chinese migrant workers actively responded to the country's call for "mass entrepreneurship and innovation", and their willingness which they return home with enthusiasm and left their job to start a new career has gradually increased. Who go home and left their job to start a new career has become a trend for migrant workers. With the gradual advancement of the rural revitalization strategy, migrant workers to start a new career have played a major role in reducing poverty and promoting economic growth, which has important practical significance for realizing rural revitalization.

The issue of migrant workers' entrepreneurship has become an issue that the central and local governments attach great importance to, and exploring the issue of migrant workers' entrepreneurship has received extensive attention from domestic academic circles. Since the 2008 financial crisis, the team of migrant workers going hometowns to start a new career has gradually grown, 
and subsequent research on migrant workers going hometowns to look for a new job has gradually increased [4]. Domestic researcher conducted a rigorous and detailed discussion on a series of problems of migrant workers based on the research of going hometowns to start a new job abroad, combined with the status quo of migrant workers returning to their hometowns in my country [5]. Therefore, this article combines the current status of migrant workers' return to their hometown to start a business, and by analysing factors affecting of going hometowns to start a new job, this article puts forward a targeted support strategy for going hometowns to start a new career.

\section{RESEARCH ON THE INFLUENCING FACTORS OF MIGRANT WORKERS RETURNING TO HOMETOWN TO START A BUSINESS}

\subsection{Factors Influencing the Willingness of Migrant Workers to Return Home}

The influencing factors' willingness of migrant workers to start a new career are mainly studied from the three levels of migrant workers, their families and the environment. First of all, from the personal aspect, the main factors that affect the entrepreneurial behavior of migrant workers include their own characteristics, personal wealth, employment experience and other factors. Studies have shown that the type of industry and the position held by migrant workers which have a obvious influence about the choice of entrepreneurial behavior [6]. Then from the family perspective, the migrant workers' entrepreneurial willingness has a certain relationship with the annual income of the entire family; finally, from the environmental perspective, the factors of entrepreneurial willingness not only come from the local infrastructure condition of entrepreneurship, but also come from the entrepreneurial support and entrepreneurial culture of the local government. The impact of [7].

\subsection{Factors Influencing the Behaviour of Peasant Workers Returning to Hometown}

From the perspective of entrepreneurs, the main research is the impact of migrant workers' human capital [8], social capital [9], economic capital [10], etc. Behaviour related to entrepreneurship of migrant workers go home and left their job. Specifically, human capital and social capital are the direct influencing factors of entrepreneurial behavior and willingness to return home. Economic capital is rarely mentioned in the existing studies, and its impact is uncertain. Psychological capital not only has a significant impact on the risk appetite of migrant workers, but also has an important impact on entrepreneurial decision-making. Then it discusses the influence of the new rural culture on the behavior of migrant workers going home with enthusiasm and left their job to start a new career. Studies have shown that the new rural culture significantly affects the entrepreneurial behavior of returning migrant workers. Finally, in terms of entrepreneurial opportunities identification, the researchers found that the ability of migrant workers to identify opportunities in their hometowns and the degree of identification will affect their entrepreneurial behavior.

\subsection{Factors Influencing the Performance of Migrant Workers Returning to Hometown}

From a micro level, farmers' work is the mainstay of returning home to start a business, and factors such as their education level, working time abroad, and entrepreneurial experience have a significant impact on entrepreneurial performance. Specifically, migrant workers with higher levels of education and entrepreneurial experience can better improve entrepreneurial performance. Then from a meso level, the entrepreneurial performance of migrant workers returning to their hometowns is affected by the social network structure, and good social network relationships have a positive effect on entrepreneurial performance. Finally, from a macro perspective, the performance of migrant workers returning to their hometowns to start a business is affected by the social culture and policy environment. The social culture and policy environment can create an entrepreneurial atmosphere and provide a good entrepreneurial environment, which has a significant impact on the entrepreneurial performance of migrant workers returning to their hometowns.

\subsection{Research on the Entrepreneurship Environment of Migrant Workers Returning to Hometown}

The research on the entrepreneurial environment of migrant workers which return home with enthusiasm and left their job to start a new career mainly includes policy environment, cultural environment, entrepreneurial service environment, natural resource environment, financial support environment, etc. In terms of policy environment, the government has issued relevant policies, with returning farmers' work as the main body of research, and rural innovation and entrepreneurship as the research objective, to further improve and optimize the rural entrepreneurship policy environment. In terms of cultural environment, the rural culture in the new era changes the rural landscape and affects the values of people's lives. These changes provide more opportunities for migrant workers to go hometowns to start a new career. In terms of entrepreneurial service environment, government departments create an entrepreneurial atmosphere by providing entrepreneurial service channels. In terms of the natural environment, there are rural resources that can be developed in rural areas. 
Returning migrant workers develop an industrial chain based on local resources to offer entrepreneurial advantages to migrant workers.

\section{RESEARCH ON SUPPORTING STRATEGIES FOR CHINESE MIGRANT WORKERS RETURNING TO HOMETOWN TO START A BUSINESS}

\subsection{Create Entrepreneurial Atmosphere and Enhance Entrepreneurial Awareness}

Migrant workers returning to their hometowns to start businesses should focus on creating a good entrepreneurial atmosphere. First, local leaders should actively promote going hometowns to start a new career, and invite migrant workers who have successfully returned to their hometowns to share their experience. On the one hand, they can solve entrepreneurial problems in a targeted manner. To enhance the confidence of migrant workers in entrepreneurship. The second is that local leaders play an exemplary role to find reliable and suitable entrepreneurial projects to effectively reduce the risk of migrant workers to start a new job, increase opportunities for entrepreneurship practice, and provide powerful assistance to migrant workers going to hometowns to start a new career. The third is to make reasonable use of online platforms and various information dissemination channels to publicize the deeds of migrant workers to start a new job, and encourage migrant workers to actively participate in returning home business projects. In addition, share entrepreneurial knowledge through online platforms to enhance the awareness of migrant workers to go home.

\subsection{Training Entrepreneurial Skills to Improve Entrepreneurial Ability}

In terms of the inclusive public service system, the local government should create an entrepreneurial atmosphere for migrant workers to start new jobs to guide them to join the entrepreneurial team. Migrant workers have insufficient experience and ability to start businesses when they go home. The first government should carry out entrepreneurial training in a planned and organized manner to effectively supplement the entrepreneurial knowledge, management experience, and entrepreneurial skills of migrant workers to improve the management level of migrant workers. Second, in addition, the government organizes entrepreneurship exchange meetings, inviting successful farmers to share entrepreneurial experience, encouraging migrant workers to participate in entrepreneurial exchanges, on the one hand, to solve the puzzle of migrant workers in starting a business, on the other hand, to enhance their confidence in entrepreneurship. Third, the government hires experts and scholars to answer the problems encountered by migrant workers in starting a business, teach advanced enterprise management systems, and effectively guide migrant workers to improve their entrepreneurial thinking. At the same time, it provides entrepreneurial advice based on the actual conditions of rural entrepreneurship and entrepreneurial environment.

\subsection{Increase Support and Improve Financial Services}

In terms of the venture capital financing system, a scientific and effective venture capital financing mechanism has been established to provide effective assistance to entrepreneurial migrant workers. To improve the rural financial service environment, migrant workers need financial support to start new jobs. Funds have become a fundamental condition for returning migrant workers to start new jobs. Financing channels for migrant workers are limited. They actively innovate financial products and improve financial service quality. In terms of financial support environment, the government provides powerful financial assistance to migrant workers, exploring and innovating the government financial support system. On the one hand, rural financial services should increase publicity so that migrant workers have a clear understanding of financial products, especially for migrant workers who live in remote areas far away from financial service outlets. Financial institutions must do their work in a solid way, but also do their work in all respects. Vigorously support migrant workers in their hometowns to start businesses. On the other hand, taking into account the long loan issuance cycle, financial service points should simplify the loan issuance process to meet the capital needs of migrant workers in a timely manner.

\subsection{Build Infrastructure and Improve the Entrepreneurial Environment}

There are certain difficulties for migrant workers going home to start new jobs, such as land for entrepreneurship and transportation facilities. These practical difficulties have limited the prospects for the development of migrant workers going home to start a business to a certain extent. The government and other relevant departments should take effective measures to improve the entrepreneurial environment in response to the difficulties faced by entrepreneurial infrastructure. First, the application of migrant workers to go home to start new jobs faces complicated approval procedures, which increases the restrictions on migrant workers creating a brilliant career. Simplify the procedures and approval procedures for migrant workers to create a promising career, improve service levels, improve service attitudes, and relax restrictions on migrant workers return home with enthusiasm and left their job to 
start a new career. Second, rationally plan rural entrepreneurial resources, develop entrepreneurial parks in a scientific and planned manner, and introduce corresponding entrepreneurial projects based on local entrepreneurial resources. Carry out infrastructure construction around entrepreneurial resources. Third, establish and improve the guarantee mechanism for migrant workers to return home with enthusiasm to create a promising career, improve the rural public service system, and provide strong guarantees for migrant workers to start their own businesses. On the one hand, they will enhance the ability of migrant workers to resist risks when they return to their hometowns and provide effective support for migrant workers to start businesses on the other hand.

\section{CONCLUSIONS}

Which the migrant workers return home with enthusiasm and left their job to start a new career is gradually growing, the thinking of migrant workers going home for entrepreneurship is greatly improved, their awareness of starting a promising career has been gradually strengthened, and their entrepreneurial ability has been greatly improved. During the practice of migrant workers going home with enthusiasm and left their job to start a new career, the support system for migrant workers returning home in my country has been continuously improved. The migrant workers start a business in their hometown can give full play to the important entrepreneurial advantages of rural areas, solve local entrepreneurship and employment problems, and ease the employment pressure of migrant workers.

\section{ACKNOWLEDGMENTS}

This work was supported by the Fund Project: General Project of the National Social Science Fund "Research on the Mechanism and Path of the Highquality Development of Ethnic Village Tourism Leading Rural Rejuvenation" (No. 20BMZ128)

\section{REFERENCES}

[1] Cao Zongping. Risk categories and countermeasures for returning rural migrant workers to enter the agricultural field to start businesses [J]. Zhongzhou Academic Journal, 2019(04):38-44. (In Chinese)

[2] Wang Yi, Xiong Wen. Returning to the hometown to start a business: an important starting point for implementing the strategy of rural revitalization [J]. Social Sciences in Chinese Universities, 2018(06): 37-45. (In Chinese)

[3] National Bureau of Statistics. 2019 Migrant Workers Monitoring Survey Report [J]. Architecture, 2020(11): 28-31. (In Chinese)
[4] Zhang Hongru, Wang Bei, Peng Wei, Li Qun. Entrepreneurship environment, entrepreneurial cognition and entrepreneurial competence: a theoretical framework for the promotion of entrepreneurship by the new generation of migrant workers [J]. Zhejiang Social Sciences, 2018(08): 83- 88+157-158. (In Chinese)

[5] Wang Xinyu, Chen Xiongying, Zou Jiangang, Ren Qimin. Retrospect and prospect of the research on the influencing factors of migrant workers returning to their hometowns in my country $[\mathrm{J}]$. Journal of Beijing Union University (Humanities and Social Sciences Edition), 2018, 16(03): 86-99. (In Chinese)

[6] Yang Jianchun, Wang Jialian. Retrospect and Prospect of Research on Tourism Poverty Alleviation in Ethnic Areas-Based on Bibliometric Analysis [J]. Guizhou Ethnic Studies, 2019, 40(08): 118-124. (In Chinese)

[7] Su Weilin, Lin Xinqi. Research on the evolution of hotspots and frontier trends in the field of domestic organizational innovation based on knowledge graphs $[\mathrm{J}]$. Journal of Southwest University for Nationalities (Humanities and Social Sciences Edition), 2018, 39(03):227-233. (In Chinese)

[8] Li Jun. Human capital and urban entrepreneurial performance of migrant workers $[\mathrm{J}]$. Journal of South China Agricultural University (Social Science Edition), 2018, 17(06): 42-51. (In Chinese)

[9] Wang Xinyu, Wu Keqiang, Zhao Xin, Chen Xiongying. The transformation mechanism of returning migrant workers from opportunistic entrepreneurial willingness to entrepreneurial behavior: a narrative study based on entrepreneurial context [J]. Journal of Beijing Union University (Humanities and Social Sciences Edition), 2020, 18(02):96-106. (In Chinese)

[10] Li Mei. An analysis of the factors affecting the entrepreneurship of female migrant workers returning to their hometowns in ethnic areasBased on the micro, meso, and macro perspectives [J]. Guizhou Social Sciences, 2012(02): 88-90. (In Chinese) 